\title{
Endophytic Fungi of Salt-Tolerant Plants: Diversity and Ability to Promote Plant Growth
}

\author{
Irina Khalmuratova ${ }^{1 \dagger}$, Doo-Ho Choi ${ }^{1 \dagger}$, Jong-Guk Kim ${ }^{1}$, and In-Seon Lee ${ }^{2 *}$ \\ 'School of Life Science and Biotechnology, Kyungpook National University, Daegu 41566, Republic of Korea \\ ${ }^{2}$ Department of Food Science and Technology, Keimyung University, Daegu 42601, Republic of Korea
}

Suaeda australis, Phragmites australis, Suaeda maritima, Suaeda glauca Bunge, and Limonium tetragonum in the Seocheon salt marsh on the west coast of the Korean Penincula were sampled in order to identify the endophytes inhabiting the roots. A total of 128 endophytic fungal isolates belonging to 31 different genera were identified using the fungal internal transcribed spacer (ITS) regions and the $5.8 \mathrm{~S}$ ribosomal RNA gene. Fusarium, Paraconiothyrium and Alternaria were the most commonly isolated genera in the plant root samples. Various diversity indicators were used to assess the diversity of the isolated fungi. Pure cultures containing each of the 128 endophytic fungi, respectively, were tested for the plant growth-promoting abilities of the fungus on Waito-C rice germinals. The culture filtrate of the isolate Lt-1-3-3 significantly increased the growth of shoots compared to the shoots treated with the control. Lt-1-3-3 culture filtrate was analyzed and showed the presence of gibberellins (GA, $2.487 \mathrm{ng} / \mathrm{ml}_{1}, \mathrm{GA}_{3} 2.592 \mathrm{ng} / \mathrm{ml}, \mathrm{GA}_{9} 3.998$, and $\mathrm{GA}_{24} 6.191 \mathrm{ng} / \mathrm{ml}$ ). The culture filtrate from the Lt-1-3-3 fungal isolate produced greater amounts of $\mathrm{GA}_{9}$ and $\mathrm{GA}_{24}$ than the wild-type Gibberella fujikuroi, a fungus known to produce large amounts of gibberellins. By the molecular analysis, fungal isolate Lt-1-3-3 was identified as Gibberella intermedia, with $100 \%$ similarity.

Keywords: Coastal plants, fungal diversity, fungal endophytes, plant growth-promoting activity, gibberellin

Received: June 4, 2021 Accepted: September 13, 2021

First published online: September 15, 202

* Corresponding author Phone: $+82 ? 53 ? 850 ? 5538$ Fax: $+82 ? 53 ? 850 ? 5538$ E-mail : inseon@kmu.ac.kr

Supplementary data for this paper are available on-line only at http://jmb.or.kr.

pISSN 1017-7825 eISSN 1738-8872

Copyright $(2021$ by the authors. Licensee KMB. This article is an open access article distributed under the terms and condition of the Creative Commons Attribution (CC BY) license.

\section{Introduction}

In their natural state, most plants are colonized by endophytes that can form interactions with their host. This can improve the tolerance to environmental stresses, thus improving the ecological adaptability of host plants. Symbiotic microorganisms such as endophytes are known to play an important role in the regulation of host plant growth and development processes. Stimulation of plant growth by endogenous fungi is due in part to the production of plant hormones such as gibberellins (GAs), abscisic acids, cytokinins, auxins, and other plant growth-promoting substances. Phytohormones may also confer fitness benefits to host plants, including tolerance to herbivores, salinity, diseases, heat, and drought, and may also increase shoot and root biomass [1-6]. Recent studies revealed that symbiotic fungi play a critical role in host plant survival $[7,8]$.

Gibberella intermedia is a well-known fungus isolated from plants and soil and found as a pathogen in many plants worldwide. Mycotoxins, including fusaproliferin, beauvericin, moniliformin, and fumonisin, may also be secreted by strains of G. intermedia [9]. Within the same genus, G. fujikuroi can produce gibberellins, a group of diterpenoid plant hormones that were first detected in the 1930s in a culture filtrate from this fungus. Gibberellins affect plant growth in a variety of ways, including stem growth, germination, flowering, sexual expression, dormancy, enzyme induction, and leaf-and-fruit aging. Recently, more than 136 gibberellins isolated from bacteria, fungi, and plants have been identified. Fungal strains Penicillium citrinum LWL4, Aspergillus terreus LWL5, Paecilomyces formosus LHL10, and Sphaceloma manihoticola have been reported to produce gibberellin [10-12].

Recently, interest in the destruction of natural ecosystems, especially salt marshes, has been increasing. To restore the damaged salt marshes, greening marshes by promoting the growth of native plants is essential. In this process, endophytic fungi are the key to restoration. The aims of this study were to: a) survey the distribution and diversity of endophytic fungi from a specific region of Korea, b) assess the ability of the fungal isolates to promote growth of Waito-C rice germinals, and c) to determine whether secondary metabolites, such as gibberellins, are present in fungal culture filtrates. 


\section{Materials and Methods}

\section{Collection of Plant Samples}

Five plant species were collected from the Seocheon salt marsh, located in the middle of the west coast of Korea. Within each species, two to four samples were collected at different locations at each site. In Table 1, lists of the scientific name, codes of the plants, and global positioning system information were organized. The samples were placed into zipped bags during collection, transported to the laboratory, and stored at $4^{\circ} \mathrm{C}$ until further processing for isolation of endophytes. All sample preparation was done within $36 \mathrm{~h}$ of collection.

\section{Surface Sterilization and Isolation of Endophytic Fungi from the Roots}

Samples were washed with distilled water to remove the soil particles and residues from the plant roots. Washed samples were sterilized with Tween 80 detergent solution for $5 \mathrm{~min}$ and surface of samples was sterilized by perchloric acid (1\%) solution. The samples were then washed twice with sterile distilled water. The prepared root samples were then cut into $2.0-2.5 \mathrm{~cm}$ pieces by using scissors. The pieces were cultured on Hagem minimal medium (glucose $5.0 \mathrm{~g} / \mathrm{l}$, malt extract $5.0 \mathrm{~g} / \mathrm{l}, \mathrm{NH}_{4} \mathrm{Cl} 0.5 \mathrm{~g} / \mathrm{l}, \mathrm{KH}_{2} \mathrm{PO}_{4} 0.5 \mathrm{~g} / \mathrm{l}, \mathrm{MgSO}_{4^{\circ}} 7 \mathrm{H}_{2} \mathrm{O} 0.5 \mathrm{~g} / \mathrm{l}$, and Fe-EDTA $11.3 \mathrm{mg} / \mathrm{l}$ ) containing $80 \mathrm{ppm}$ streptomycin [13]. The plates were incubated at $25^{\circ} \mathrm{C}$ until single colonies of fungi were emerged. As fungi emerged, they were transferred to potato dextrose agar (PDA; potato extract $4 \mathrm{~g} / \mathrm{l}$ and dextrose $20 \mathrm{~g} / \mathrm{l}$ ) plates for pure cultures.

DNA Extraction, PCR Amplification, and Identification of Fungal Strains

The fungal isolates were inoculated into Erlenmeyer flasks containing $50 \mathrm{ml}$ of the potato dextrose broth medium and were incubated at $25^{\circ} \mathrm{C} \pm 2{ }^{\circ} \mathrm{C}$ for 7 days on a rotary shaker at $120 \mathrm{rpm}$. Lyophilized fungal isolates were collected using vacuum. Fungal genomic DNA extracted using the DNeasy Plant Mini Kit (Qiagen, USA) was identified by amplification and sequencing of the internal transcribed spacer (ITS) region. Among the various ITS, ITS primers named ITS- 1 (5'-TCC GTA GGT GAA CCT GCG G- $3^{\prime}$ ) and ITS- 4 (5'-TCC TCC GCT TAT TGA TAT GC-3') were used in this study. The reaction cycles comprised an initial denaturation step $\left(95^{\circ} \mathrm{C}\right.$ for $2 \mathrm{~min}) ; 30$ cycles of denaturation $\left(95^{\circ} \mathrm{C}\right.$ for $\left.30 \mathrm{sec}\right)$, annealing $\left(55^{\circ} \mathrm{C}\right.$ for $\left.1 \mathrm{~min}\right)$, and extension $\left(72^{\circ} \mathrm{C}\right.$ for $\left.1 \mathrm{~min}\right)$; and a final extension $\left(72^{\circ} \mathrm{C}\right.$ for $\left.7 \mathrm{~min}\right)$. Detection of PCR production was processed using agarose gel electrophoresis with ethidium bromide staining. The products were directly purified by the QIAquick PCR Purification Kit (Qiagen). Then, purified PCR products were sequenced by the ABI PRISM BigDye Terminator Cycle Sequencing Ready Reaction Kit (PE Biosystems, USA) and an ABI 310 Genetic Analyzer (Perkin Elmer, USA). The obtained sequences were identified using the National Center for Biotechnology Information GenBank database BLASTN tool.

\section{Statistical Analysis}

Diversity of the fungal endophytes isolated from the plant samples was assessed. Diversity at the genus level was assessed using the Shannon diversity index $\left(H^{\prime}\right)$, Fisher's alpha index $(\alpha)$, and Simpson's index of diversity $(1-D)$. Richness was evaluated using Menhinick's richness index $\left(D_{m n}\right)$ and Margalef's index $\left(D_{m g}\right)$ [14-16].

\section{Effect of Fungal Filtrates on Plant Growth Promotion on Waito-C Rice Seedlings}

To test the ability of the fungal isolates to promote plant growth, Waito-C rice germinals were exposed to culture filtrates from the fungal isolates. The fungal isolates were cultured in Czapek Dox broth medium on a shaking incubator for 7 days at $25^{\circ} \mathrm{C}$ and $180 \mathrm{rpm}$ and were harvested using $20 \sim 25 \mu \mathrm{m} / 15 \mathrm{~cm}$ Whatman filter papers (Brentford, UK). The harvested fungal culture filtrates were immediately frozen at $-70^{\circ} \mathrm{C}$ and then lyophilized for concentration. The lyophilized culture filtrates were concentrated 50 times by mixing with $1 \mathrm{ml}$ of distilled water. In order to minimize the activity of gibberellins in the seed coat, Waito-C rice grains were treated with uniconazole for $24 \mathrm{~h}$. The treated seeds were washed and soaked in distilled water until radical emergence. The young seedlings were then transplanted to glass tubes with $0.6 \%$ water agar medium and the seedlings were grown in a growth chamber under conditions of $12 \mathrm{~h}$ at $25^{\circ} \mathrm{C}$ and $12 \mathrm{~h}$ at $30^{\circ} \mathrm{C}$ for a total of 5 days. After rice seedlings reached the two-leaf stage, 10 microliters of concentrated lyophilized culture filtrate from each fungal isolate was applied to the apical meristem. In order to compare with G. fujikuroi, whose performance was previously confirmed, the same amount with same concentrate as in other experimental groups was inoculated into the same site and the experiment was conducted. In this study, plant and shoot lengths of rice became apparent 1 week after application compared to rice seedlings treated with wild-type G. fujikuroi, which served as positive controls.

\section{Extraction and Quantification of Gibberellins from Fungal Culture Filtrates}

Fungal isolates were incubated for 7 days in Czapek Dox broth medium with $1 \%$ (w/v) glucose and peptone. Gibberellins were extracted from culture filtrates and were analyzed using reverse-phase $\mathrm{C}_{18}$ high-performance

Table 1. Geographic coordinates and scientific names of plants native to the Seocheon salt marsh.

\begin{tabular}{clccc}
\hline No & Scientific name & Code & Site of collection & Habitat \\
\hline 1 & Suaeda australis & $\mathrm{Sa}$ & $36^{\circ} 3^{\prime} 18.55^{\prime \prime} \mathrm{N} / 126^{\circ} 38^{\prime} 24.08^{\prime \prime} \mathrm{E}$ & Halophytic \\
2 & Phragmites australis & $\mathrm{Pa}$ & $36^{\circ} 2^{\prime} 45.24^{\prime \prime} \mathrm{N} / 126^{\circ} 39^{\prime} 17.66^{\prime \prime} \mathrm{E}$ & Halophytic \\
3 & Suaeda maritima & $\mathrm{Sm}$ & $36^{\circ} 3^{\prime} 18.76^{\prime \prime} \mathrm{N} / 126^{\circ} 38^{\prime} 26.84^{\prime \prime} \mathrm{E}$ & Halophytic \\
4 & Suaeda glauca Bunge & $\mathrm{Su}$ & $36^{\circ} 3^{\prime} 18.76^{\prime \prime} \mathrm{N} / 126^{\circ} 38^{\prime} 22.32^{\prime \prime} \mathrm{E}$ & Halophytic \\
5 & Limonium tetragonum & $\mathrm{Lt}$ & $36^{\circ} 3^{\prime} 18.59^{\prime \prime} \mathrm{N} / 126^{\circ} 38^{\prime} 23.60^{\prime \prime} \mathrm{E}$ & Halophytic \\
\hline
\end{tabular}


liquid chromatography. With selected ion monitoring (SIM), fractions were then prepared for gas chromatography (GC) with mass spectrometry (MS). Three major ions of the added $\left[{ }^{2} \mathrm{H}_{2}\right]$ gibberellin internal standards and gibberellins were monitored simultaneously. Retention time calculations involved calculating the Kovats retention index using hydrocarbon standards. Gibberellins were quantified using the peak area ratios between un-deuterated and deuterated gibberellins.

\section{Results and Discussion}

Molecular Identification of Endophytic Fungi

The nucleotide sequences of endophytic fungal isolates from the Seocheon salt marsh were grouped by host plant species and registered in GenBank with the following accession numbers: S. australis (KP017930KP017952), P. australis (KP017953-KP017967), S. maritima (KP017968-KP017981), S. glauca Bunge (KP017982KP018018), and L. tetragonum (KP018019-KP018057). In table 1, the accession numbers of fungal isolates were listed. Total 128 fungal isolates, representing 31 genera and 37 species, were isolated from plants on the west coast of Korea.

The 128 isolates were classified as 2 phyla, Ascomycota and Basidiomycota. The Dothideomycetes class (57 strains) accounted for the greatest number of strains, followed by Sordariomycetes ( 49 strains), Eurotiomycetes (17 strains), Ustilaginomycetes (3 strains), Agaricomycetes (1 strain), and Leotiomycetes (1 strain). At the genus level, Fusarium accounted for the highest number of strains (23 strains), followed by Paraconiothyrium (15 strains), and Alternaria (14 strains).

Endophytic fungi were also analyzed at the class and genus levels (Fig. 1) and Dothideomycetes was found to account for the highest percentage of isolates at the class level. Except for the isolates from the plant L. tetragonum, Dothideomycetes accounted for more than a half of all of the fungal isolates in every plant sample. Fusarium was the most prevalent (18\%) among all of the fungal strains, followed by Paraconiothyrium (11.7\%), and Alternaria (10.9\%). The remaining genera of the fungal isolates constituted only $0.7-7 \%$ of the strains. A study by Nalini et al. (2014) showed that fungi from the Fusarium genus are the most salient fungi discovered in stem and root fragments of medicinal plants that are native to the western coast of the Indian peninsula [17]. Fungal species

A

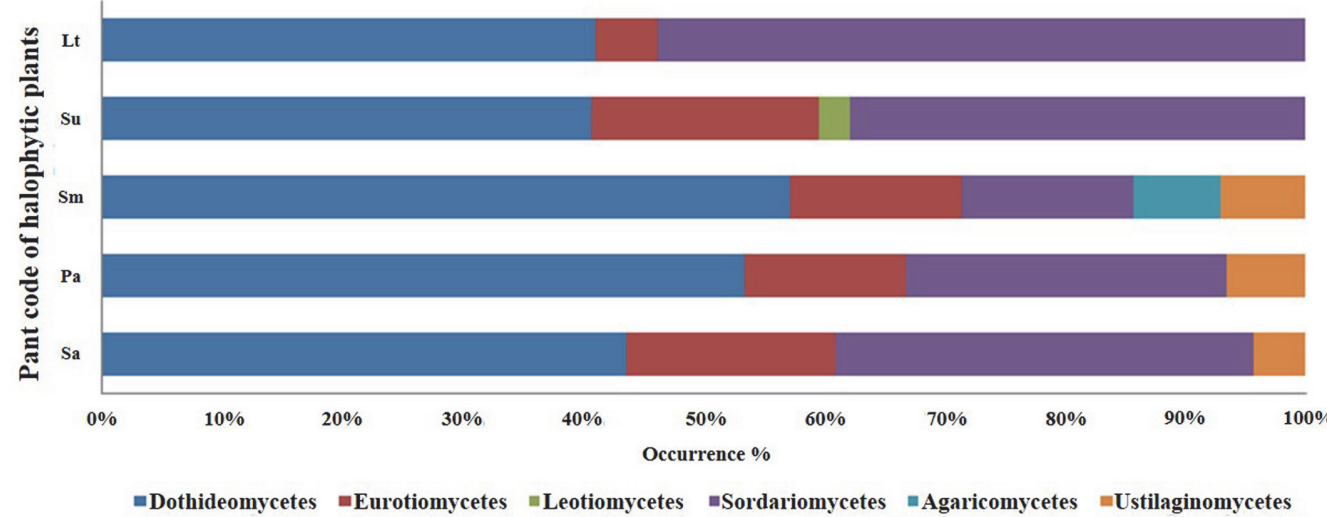

B

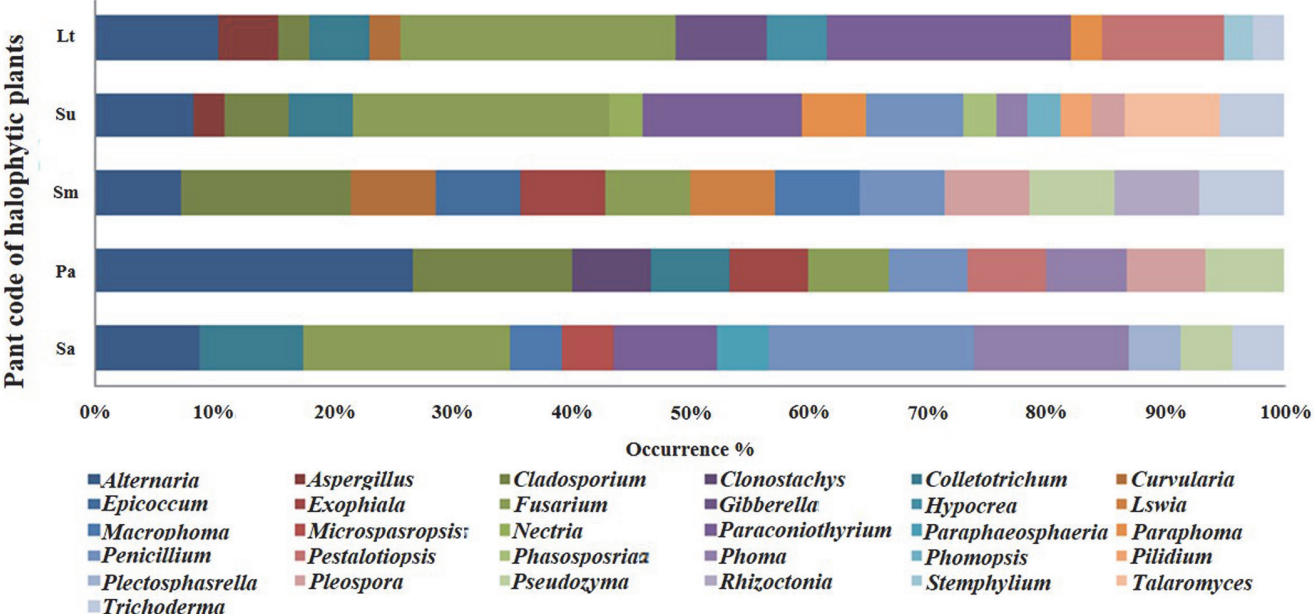

Fig.1. Distribution of fungal isolates in different plant samples at the class (A) and genus (B) levels. Sa, Suaeda australis; Pa, Phragmites australis; Sm, Suaeda maritima; Su, Suaeda glauca Bunge; and Lt, Limonium tetragonum. 
abundant in the host, including fungi from the genera Fusarium, Alternaria, and Penicillium can associate with plants $[18,19]$.

\section{Diversity of Endophytic Fungi Isolated from Halophytes}

In Table 2, more details of fungal components were organized. Depending on the plants, fungal isolates from $S$. australis were classified as 12 genera and 11 species. Isolates from P. australis were classified as 11 genera and 8 species. Isolates from S. maritima were classified as 13 genera and 8 species. Isolates from S. glauca Bunge were classified as 16 genera and 16 species. Fungal isolates from $L$. tetragonum were classified as 13 genera and 17 species.

The richness and diversity of the fungal isolates were analyzed at the genus level and more detail of fungal

Table 2. Endophytic fungi ( 128 isolates) isolated from plant species with scientific names, plant codes, taxa of fungal isolates, and number of isolates.

\begin{tabular}{cccc}
\hline Scientific name of plant sample & Abbreviated plant name & Taxon of fungal strains & No. of isolates \\
\hline Suaeda australis & $\mathrm{Sa}$ & 12 genera, 11 species & 23 \\
Phragmites australis & $\mathrm{Pa}$ & 11 genera, 8 species & 15 \\
Suaeda maritima & $\mathrm{Sm}$ & 13 genera, 8 species & 14 \\
Suaeda glauca Bunge & $\mathrm{Su}$ & 16 genera, 16 species & 37 \\
Limonium tetragonum & $\mathrm{Lt}$ & 13 genera, 17 species & 39
\end{tabular}

Table 3. Diversity indices and distribution of endophytic fungi isolated from plants native to the Seocheon salt marsh.

\begin{tabular}{|c|c|c|c|c|c|}
\hline Fungal taxon & $\mathrm{Sa}$ & $\mathrm{Pa}$ & $\mathrm{Sm}$ & $\mathrm{Su}$ & $\mathrm{Lt}$ \\
\hline Alternaria & 2 & 4 & 1 & 3 & 4 \\
\hline Aspergillus & & & & 1 & 2 \\
\hline Cladosporium & & 2 & 2 & 2 & 1 \\
\hline Clonostachys & & 1 & & & \\
\hline Colletotrichum & 2 & 1 & & 2 & 2 \\
\hline Curvularia & & & 1 & & 1 \\
\hline Epicoccum & & & 1 & & \\
\hline Exophiala & & 1 & 1 & & \\
\hline Fusarium & 4 & 1 & 1 & 8 & 9 \\
\hline Gibberella & & & & & 3 \\
\hline Hypocrea & & & & & 2 \\
\hline Lewia & & & 1 & & \\
\hline Macrophoma & 1 & & 1 & & \\
\hline Microsphaeropsis & 1 & & & & \\
\hline Nectria & & & & 1 & \\
\hline Paraconiothyrium & 2 & & & 5 & 8 \\
\hline Paraphaeosphaeria & 1 & & & & \\
\hline Paraphoma & & & & 2 & 1 \\
\hline Penicillium & 4 & 1 & 1 & 3 & \\
\hline Pestalotiopsis & & 1 & & & 4 \\
\hline Phaeosphaeria & & & & 1 & \\
\hline Phoma & 3 & 1 & & 1 & \\
\hline Phomopsis & & & & 1 & \\
\hline Pilidium & & & & 1 & \\
\hline Plectosphaerella & 1 & & & & \\
\hline Pleospora & & 1 & 1 & 1 & \\
\hline Pseudozyma & 1 & 1 & 1 & & \\
\hline Rhizoctonia & & & 1 & & \\
\hline Stemphylium & & & & & 1 \\
\hline Talaromyces & & & & 3 & \\
\hline Trichoderma & 1 & & 1 & 2 & 1 \\
\hline$N$ & 23 & 15 & 14 & 37 & 39 \\
\hline$S$ & 12 & 11 & 13 & 16 & 13 \\
\hline Shannon diversity index $\left(H^{\prime}\right)$ & 2.33 & 2.25 & 2.54 & 2.53 & 2.25 \\
\hline Simpson's index of diversity $(1-D)$ & 0.93 & 0.93 & 0.99 & 0.92 & 0.89 \\
\hline Menhinick's index $(\mathrm{Dmn})$ & 2.50 & 2.84 & 3.47 & 2.63 & 2.08 \\
\hline Margalef's index (Dmg) & 3.51 & 3.69 & 4.55 & 4.15 & 3.28 \\
\hline Fisher's diversity $(\alpha)$ & 10.12 & 18.60 & 88.78 & 10.71 & 6.83 \\
\hline
\end{tabular}

Sa, Suaeda australis; Pa, Phragmites australis; Sm, Suaeda maritima; Su, Suaeda glauca Bunge; and Lt, Limonium tetragonum; , total number of individuals in each samples; $S$; number of different genera in a sample. 
information was arranged on the Table 3. For general abundance calculated using Menhinick and Margalef indices, S. maritima scored the highest at 3.47 and 4.55, respectively. In terms of genetic diversity, which was calculated using Shannon's, Fisher's $\alpha$, and Simpson's indices, S. maritima had the highest scores of 2.54, 88.78, and 0.99 , respectively. The diversity scores vary greatly because the diversity indices are based on the proportional abundance of genera in a sample, and are more sensitive toward genus evenness [20]. The S. maritima specimen had the highest diversity indices, indicating the most diverse fungal community isolated from this plant.

Bioassay for Plant Growth-Promoting Effects of Fungal Culture Filtrates on Waito-C Rice Seedlings

The culture filtrate from the Lt-1-3-3 fungal isolate was superior to that of G. fujikuroi in promoting plant growth, as the average shoot length of plants exposed to Lt-1-3-3 was $9.3 \mathrm{~cm}$ and the plant length was $20.1 \mathrm{~cm}$ in Waito-C seedlings (Fig. 2). These results are consistent with those of another study in which the endophytic fungus $P$. citrinum, isolated from the roots of Ixeris repens, was shown to promote the growth of Waito-C rice and Atriplex gemelinii seedlings [21].

To confirm the presence of gibberellins, microbial culture filtrates were screened to identify biologically active molecules. Waito-C rice seedlings were used for the detection of plant growth-promoting hormones in the culture

A

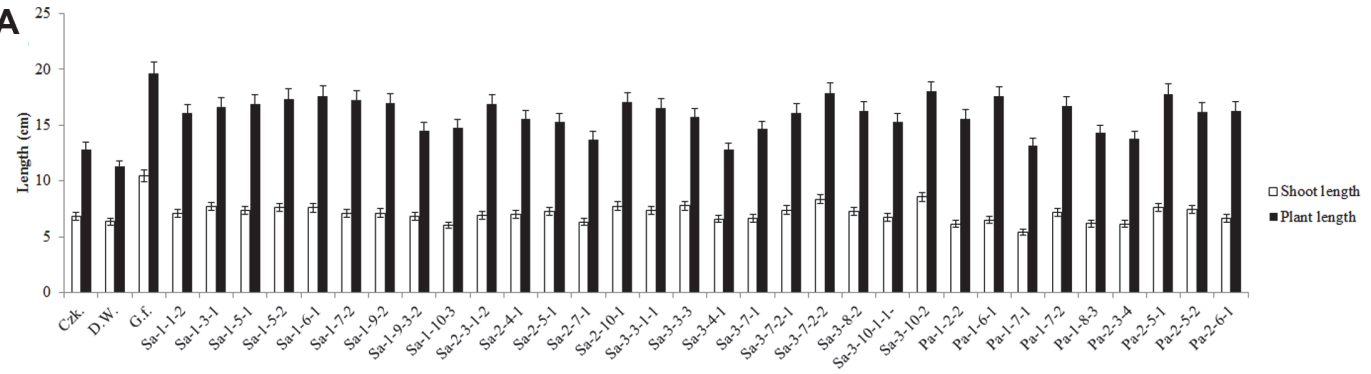

B

${ }^{25}$

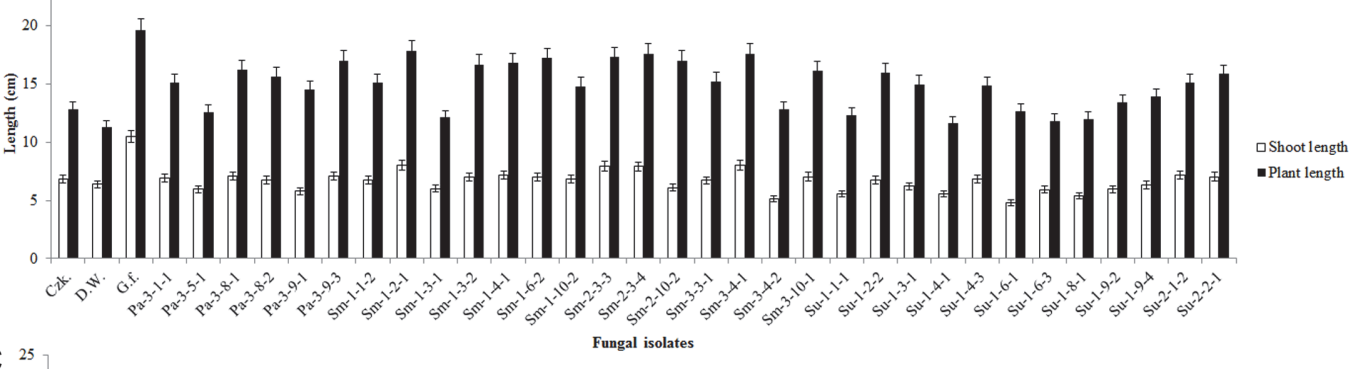

C

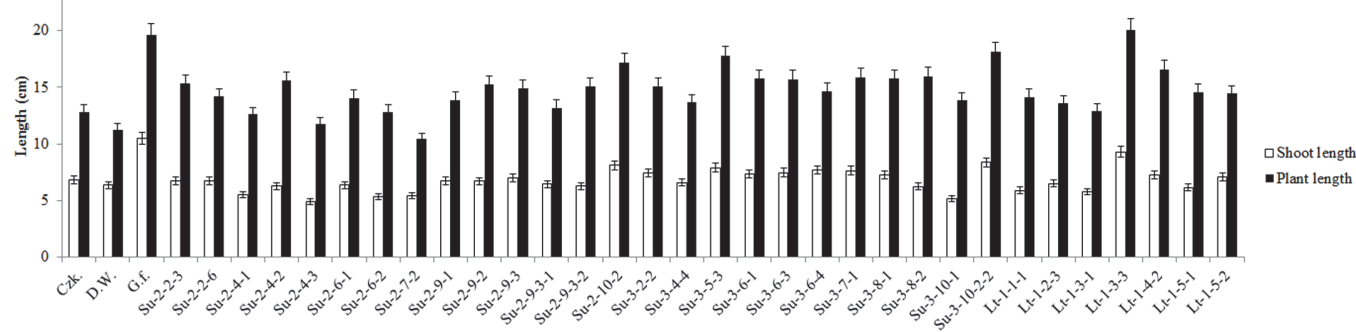

D

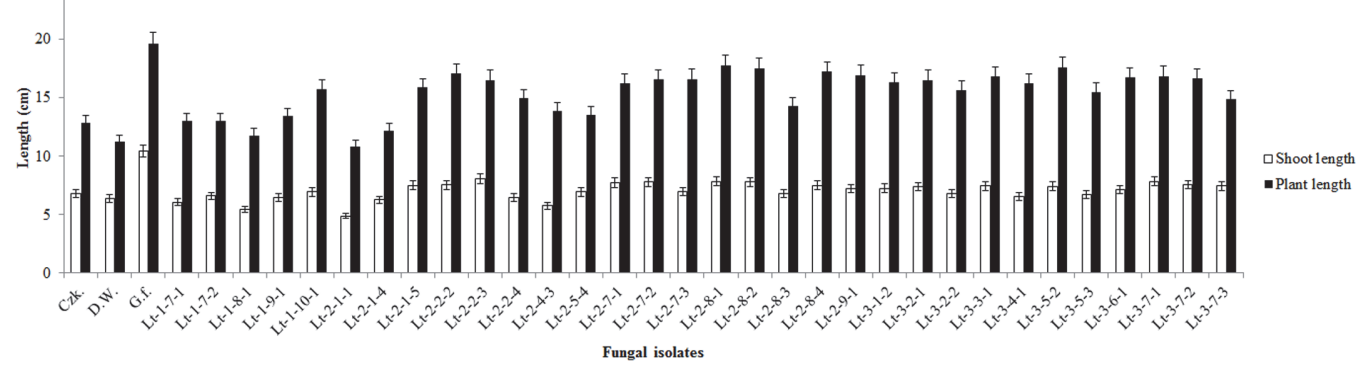

Fig. 2. Bioassay for plant growth promoting of Waito-C rice seedlings with culture filtrates of fungi isolated from the plant samples (A-D). Ten microliters of lyophilized culture filtrates was treated to Waito-C rice seedlings. The shoot length and plant length of the Waito-C rice seedlings were measured after 7 days of treatment. The standard deviation from means was calculated using Microsoft Excel. Czk., Czapek Dox broth media; D.W., distilled water; G.f., Gibberella fujikuroi. 


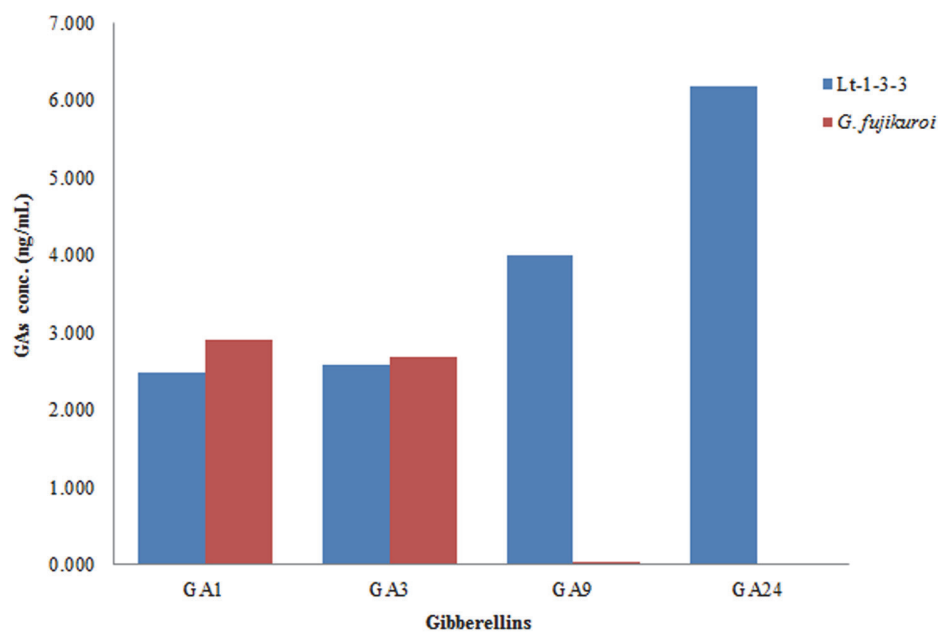

Fig. 3. Gibberellins content of fungal culture filtrate of the Lt-1-3-3 isolate and wild type Gibberella fujikuroi. GC/MS SIM analysis of culture filtrate extracts from the Lt-1-3-3 fungal isolate detected two bioactive GAs. Lt-1-3-3 showed the presence of bioactivity of GA1, GA3, and other inactive GAs.

filtrates of the fungal endophytes isolated from the roots of halophytes. Waito-C rice is a known dwarf rice cultivar with reduced biosynthesis of gibberellins. Waito-C seeds were treated with uniconazole as a gibberellin biosynthesis inhibitor. The Lt-1-3-3 fungal isolate, which has plant growth-promoting capacity (Fig. 2), was analyzed using Waito-C rice seedlings.

\section{Quantitative Analysis of Culture Filtrates of Lt-1-3-3 for the Presence of Gibberellins}

The plant growth-promoting activity of the culture filtrate of the fungus Lt-1-3-3 isolated from Waito-C rice germinals was confirmed. Analysis of gibberellin in this culture filtrate revealed the presence of $\mathrm{GA}_{1}(2.487 \mathrm{ng} / \mathrm{ml})$, $\mathrm{GA}_{3}(2.592 \mathrm{ng} / \mathrm{ml}), \mathrm{GA}_{9}(3.998 \mathrm{ng} / \mathrm{ml})$, and $\mathrm{GA}_{24}(6.191 \mathrm{ng} / \mathrm{ml})$. Fungal isolate Lt-1-3-3 produced significantly greater amounts of $\mathrm{GA}_{9}$ and $\mathrm{GA}_{24}$ than wild-type $\mathrm{G}$. fujikuroi, which produced $\mathrm{GA}_{1}(2.909 \mathrm{ng} / \mathrm{ml}), \mathrm{GA}_{3}(2.695 \mathrm{ng} / \mathrm{ml})$, $\mathrm{GA}_{9}(0.043 \mathrm{ng} / \mathrm{ml})$, and $\mathrm{GA}_{24}(0.026 \mathrm{ng} / \mathrm{ml})$ in the present study (Fig. 3).

Including gibberellins, various secondary metabolites are known to be produced from fungal endophytes. The GC/MS with the SIM method makes it possible to analyze the complex mixtures and detect the compounds of different classes. Therefore, we used this technique for the cultural analysis of the Lt-1-3-3 fungal isolate. GC/MS SIM is helpful for the analysis of a number of compounds and is often used in plant experimentation. Due to its reliability, GC/MS SIM has been previously used in quantitative analyses of various plant hormones [22, 23].

In summary, 128 fungal isolates are isolated from 5 species of coastal plants. These fungal isolates were classified into 2 phyla, 6 classes, 12 orders, 17 families, and 31 genera. The dominant genus was Fusarium (class Sordariomycetes), followed by Paraconiothyrium and Alternaria. Based on the diversity analysis, the most diverse fungi were the endophytic fungi isolated from S. maritima. Culture filtrates from the 128 fungal isolates were assessed on Waito-C rice seedlings and the filtrate from fungal isolate Lt-1-3-3 exhibited excellent plant growthpromoting capacity. This isolate was confirmed to produce gibberellins $\mathrm{GA}_{1}, \mathrm{GA}_{3}, \mathrm{GA}_{9}$, and $\mathrm{GA}_{24}$. Using sequence homology, the Lt-1-3-3 isolate was identified as G. intermedia. This study provides basic data on the microbial resources present in plants from coastal salt marshes.

\section{Acknowledgments}

This study was supported by the Basic Science Research Program through the National Research Foundation of Korea (NRF), Ministry of Education (2016R1A6A1A05011910), Research Institute for Dok-do and Ulleung-do Island of Kyungpook National University, and Korea Ministry of Environment as "The Eco-Innovation Project".

\section{Conflict of Interest}

The authors have no financial conflicts of interest to declare.

\section{References}

1. Rodriguez R, Redman R. 2008. More than 400 million years of evolution and some plants still can't make it on their own: plant stress tolerance via fungal symbiosis. J. Exp. Bot. 59: 1109-1114.

2. Farrar K, Bryant D, Cope-Selby N. 2014. Understanding and engineering beneficial plant-microbe interactions: plant growth promotion in energy crops. Plant Biotechnol. J. 12: 1193-1206.

3. Barrow JR, Lucero ME, Reyes-Vera I, Havstad KM. 2008. Do symbiotic microbes have a role in regulating plant performance and response to stress?. Commun. Integr. Biol. 1: 69-73.

4. Waqas M, Khan AL, Kamran M, Hamayun M, Kang SM, Kim YH, et al. 2012. Endophytic fungi produce gibberellins and indoleacetic acid and promotes host-plant growth during stress. Molecules 17: 10754-10773. 
5. Vadassery J, Ritter C, Venus Y, Camehl I, Varma A, Shahollari B, et al. 2008. The role of auxins and cytokinins in the mutualistic interaction between Arabidopsis and Piriformospora indica. Mol. Plant Microbe. Interact. 21: 1371-1383.

6. Redman RS, Kim YO, Woodward CJ, Greer C, Espino L, Doty SL, et al. 2011. Increased fitness of rice plants to abiotic stress via habitat adapted symbiosis: a strategy for mitigating impacts of climate change. PLoS One 6: e14823.

7. Nair DN, Padmavathy S. 2014. Impact of endophytic microorganisms on plants, environment and humans. Sci. World J. $22: 2014$.

8. Pusztahelyi T, Holb IJ, Pócsi I. 2015. Secondary metabolites in fungus-plant interactions. Front. Plant Sci. 6: 573.

9. Leslie JF, Zeller KA, Logrieco A, Mulè G, Moretti A, Ritieni A. 2004. Species diversity of and toxin production by Gibberella fujikuroi species complex strains isolated from native prairie grasses in Kansas. Appl. Environ. Microbiol. 70: 2254-2262.

10. Waqas M, Khan AL, Hamayun M, Shahzad R, Kang SM, Kim JG, et al. 2015. Endophytic fungi promote plant growth and mitigate the adverse effects of stem rot: an example of Penicillium citrinum and Aspergillus terreus. J. Plant Interact. 10: 280-287.

11. Khan AL, Hamayun M, Radhakrishnan R, Waqas M, Kang SM, Kim YH, et al. 2012. Mutualistic association of Paecilomyces formosus LHL10 offers thermotolerance to Cucumis sativus. Antonie Van Leeuwenhoek 101: 267-279.

12. Zeigler RS, Powell LE, Thurston HD. 1980. Gibberellin A4 production by Sphaceloma manihoticola, causal agent of cassava superelongation disease. Phytopathology 70: 589-593.

13. Khan AL, Waqas M, Hussain J, Al-Harrasi A, Al-Rawahi A, Al-Hosni K, Kim MJ, Adnan M, Lee IJ. 2014. Endophytes Aspergillus caespitosus LK12 and Phoma sp. LK13 of Moringa peregrina produce gibberellins and improve rice plant growth. J. Plant Interact. 9: 731-737.

14. Fisher RA, Corbet AS, Williams CB. 1943. The relation between the number of species and the number of individuals in a random sample of an animal population. J. Anim. Ecol. 12: 42-58.

15. Jost L. 2006. Entropy and diversity. Oikos 113:363-375.

16. Hill MO. 1973. Diversity and evenness: a unifying notation and its consequences. Ecology 54: 427-432

17. Nalini MS, Sunayana N, Prakash HS. 2014. Endophytic fungal diversity in medicinal plants of Western Ghats, India. Int. J. Biodivers. 11: 2014

18. Li ZF, Wang LF, Feng ZL, Zhao LH, Shi YQ, Zhu HQ. 2014. Diversity of endophytic fungi from different Verticillium-wilt-resistant Gossypium hirsutum and evaluation of antifungal activity against Verticillium dahliae in vitro. J. Microbiol. Biotechnol. 24: $1149-1161$.

19. Kim H, You YH, Yoon H, Seo Y, Kim YE, Choo YS, et al. 2014. Culturable fungal endophytes isolated from the roots of coastal plants inhabiting Korean east coast. Mycobiology 42: 100-108.

20. Cadotte MW, Jonathan Davies T, Regetz J, Kembel SW, Cleland E, Oakley TH. 2010. Phylogenetic diversity metrics for ecological communities: integrating species richness, abundance and evolutionary history. Ecol. Lett. 13: 96-105.

21. Khan SA, Hamayun M, Yoon H, Kim HY, Suh SJ, Hwang SK, et al. 2008. Plant growth promotion and Penicillium citrinum. BMC Microbiol. 8: 231

22. Vadassery J, Ritter C, Venus Y, Camehl I, Varma A, Shahollari B, et al. 2008. The role of auxins and cytokinins in the mutualistic interaction between Arabidopsis and Piriformospora indica. Mol. Plant Microbe. Interact. 21: 1371-1383.

23. Navarro-Meléndez AL, Heil M. 2014. Symptomless endophytic fungi suppress endogenous levels of salicylic acid and interact with the jasmonate-dependent indirect defense traits of their host, lima bean (Phaseolus lunatus). J. Chem. Ecol. 40: 816-825.

24. Hughes AR, Cebrian J, Heck K, Goff J, Hanley TC, Scheffel W, et al. 2018. Effects of oil exposure, plant species composition, and plant genotypic diversity on salt marsh and mangrove assemblages. Ecosphere 9: e02207.

25. Cahoon DR, Lynch JC, Roman CT, Schmit JP, Skidds DE. 2019. Evaluating the Relationship Among Wetland Vertical Development, Elevation Capital, Sea-Level Rise, and Tidal Marsh Sustainability. Estuaries Coast. 42: 1-15. 